\title{
O uso das salas de bate-papo na internet: um estudo exploratório acerca das motivações, hábitos e atitudes dos adolescentes
}

\author{
Ana Cristina Garcia Dias \\ Centro Universitário Franciscano/Universidade Regional Integrada do Alto Uruguai \\ Yves de La Taille \\ Instituto de Psicologia da USP
}

\begin{abstract}
RESUMO
O objetivo deste estudo foi investigar motivações, hábitos e atitudes em relação às salas de bate-papo na internet entre adolescentes. Participaram 128 jovens (média de idade 17,02 anos; 61,7\% mulheres), estudantes de uma escola de ensino médio e de uma faculdade da Grande São Paulo. Eles responderam em sala de aula a um questionário desenvolvido especialmente para este estudo. A análise dos dados revelou que homens e mulheres não diferiram quanto aos motivos pelos quais utilizavam as salas de conversação, tendo predominado as opções "se divertir" e "conhecer pessoas". Um percentual significativamente superior de mulheres (em comparação ao de homens) indicou criar personagens ao entrar nas salas de conversação, enquanto um maior percentual de homens (comparado às mulheres) declarou achar mais fácil conversar sobre assuntos íntimos nas salas de conversação do que em uma relação face a face (por se sentirem mais protegidos no primeiro ambiente). A grande maioria dos participantes indicou que não busca as salas de bate-papo para resolver problemas pessoais, embora cerca de um quarto tenha reconhecido que as conversas nas salas os ajudam a se conhecer melhor. Conclui-se que as salas de bate-papo são vistas principalmente como um ambiente para diversão, não necessariamente implicam em formas diferenciadas das relações face a face.
\end{abstract}

Palavras-chave: internet; comunicação; adolescência.

\section{ABSTRACT \\ The use of chat rooms in the internet: an exploratory study about the motivations, habits and attitudes of adolescents}

The present study aims at investigating adolescents' motivations, habits and attitudes in the use of internet chatrooms. 128 São Paulo High School and University students answered a specially devised questionnaire. Results showed no significant gender differences concerning the reasons for using chatrooms. The most frequent motivations were "having fun" and "meeting people". More female subjects admitted to relying on ficticious characters when interacting in chatrooms, while more male subjects considered it easier to disclose personal matters in chatrooms than in face-to-face interactions (they seem to feel more protected in the virtual space). Most participants tended not to use chatrooms in order to solve personal problems, although one fourth of the sample recognized that the chats contributed to learning about oneself. As a conclusion, chatrooms are mainly seen as an environment for having fun, unable to foster a significantly different type of communication from the one(s) established in face-to-face interactions.

Keywords: internet; communication; adolescence.

O mundo virtual (seja através do computador ou dos serviços telefônicos tipo disk-point ou love-line) está permitindo a construção de novas formas de interação. Ele possui características muito particulares que o diferenciam das interações que ocorrem face a face. No ambiente virtual os meios pelos quais se pode comunicar são mais restritos, o que pode ser interpretado tanto como algo positivo quanto negativo. Por um lado, os ambientes virtuais trazem a possibilidade de se estabelecer uma comunicação no anonimato, caracterizando-se como um espaço lúdico de experimentação para as pessoas, que não precisam 
assumir responsabilidades por seus atos (e/ou palavras). Cada indivíduo pode assumir diferentes papéis sem se comprometer com nenhum. Por outro lado, a ausência de identificação pessoal possibilita a falta de ética e a mentira. Não há algo que assegure que o que está sendo dito seja verdadeiro (e muitas vezes não se deseja que essas interações ultrapassem as fronteiras da fantasia). De um modo ou de outro, a ausência de identificação permite às pessoas falarem sobre fantasias, desejos e angústias mais facilmente. Na verdade, essa é uma das razões apontadas para a procura por este tipo de "encontro" - o compartilhamento de idéias e sentimentos com o mínimo de compromisso (Schnarch, 1997; Wysocki, 1998).

A internet (e as salas de bate-papo mais especificamente) parece estar promovendo modificações importantes na forma das pessoas se relacionarem, especialmente no que tange à revelação de aspectos íntimos do si mesmo. Ela parece estar propiciando um novo ambiente, mais seguro, para a exposição de si isenta de constrangimentos e sanções sociais devido às características do contexto. Alguns autores, inclusive, sugerem que a rede estaria permitindo uma melhor expressão do verdadeiro self que as relações face a face (Bargh, Mckenna \& Fitzsimons, 2002).

Para alguns a rede constitui-se em um evento cultural sem precedentes na história da humanidade, pois traz benefícios a todos os setores da atividade humana. A possibilidade de comunicação, acesso e de transmissão de saber seriam ilimitados (Berton, 2000; Lajoie, 1998). Inclusive, fala-se de um aumento no poder individual dos cidadãos que, devido ao acesso mais democrático à informação, podem se informar melhor e tomar melhores decisões a respeito de diferentes aspectos de suas vidas (por exemplo, na escola, no trabalho ou em relação à própria saúde). A internet é vista como um recurso que amplia as possibilidades de relacionamento social, uma vez que ela permite aos usuários superar restrições geográficas e mesmo o isolamento social causado por preconceitos, doenças ou problemas de horários da vida cotidiana (Berton, 2000). Além disso, os relacionamentos na rede são construídos em torno de interesses comuns, estando menos sujeitos às interferências de questões relativas a tempo, espaço e aparência física que permeiam as relações face a face, o que possibilita aos sujeitos envolvidos na comunicação uma interação mais franca e objetiva (Schnarch, 1997; Wysocki, 1998).

Em contraposição, outros autores argumentam que a internet isola os indivíduos, limita suas relações sociais e pode levar à dependência e ao desinvesti- mento da realidade cotidiana (Leon \& Rotunda, 2000; Turkle, 1995). A internet, segundo esta linha de pensamento, estaria colocando em risco nossa vida privada, pois informações pessoais podem ser obtidas com o uso de má fé e posteriormente utilizadas para causar danos às pessoas. É o caso, por exemplo, de indivíduos pedofílicos que podem encontrar suas potenciais vítimas através da rede (Griffits, 1997). Existe ainda a ausência de segurança a respeito de dados confidenciais dos usuários, o que pode gerar formas de controle social. Por exemplo, Griffits (2000) relata que crianças no Estados Unidos, além de estarem sujeitas à exposição da pornografia, podem ser exploradas por comerciantes através da internet. Comerciantes utilizam esse meio para obter informações privadas de crianças através de sites direcionados a essa população, com o objetivo de traçar perfis individuais e criarem propagandas voltadas especificamente para elas.

No Brasil a utilização da internet é cada vez mais significativa. O Brasil é o segundo o país no mundo em permanência na $W e b$, só ficando atrás dos japoneses (Ibope, 2004). Ainda de acordo com dados do Ibope (2002), cerca de 6\% da população das nove principais cidades do Brasil utilizavam o computador para acessar a internet em julho de 1998, sendo que este número passou para $20 \%$ em maio de 2001 . Além de "navegar" pela rede, enviar e receber e-mails, a pesquisa verificou que uma substancial parcela dos usuários também utilizava as salas de bate-papo disponíveis na internet (Ibope, 2002). Estes dados atestam a crescente importância que a comunicação por computador vem assumindo na vida das pessoas, e evidenciam a necessidade de melhor compreendermos as características deste meio a fim de podermos avaliar as suas possíveis repercussões sobre os indivíduos.

Nicolaci-da-Costa (1998), observando o crescimento e a importância da utilização da internet no cotidiano dos brasileiros, teceu um conjunto de considerações sobre os impactos do uso das salas de batepapo na vida de usuários da rede. Através de impressões pessoais, de leituras de material especializado e de depoimentos obtidos em uma pesquisa empírica (20 entrevistas e 83 questionários) a autora oferece uma extensa descrição introdutória da utilização da internet no Brasil. Em seu livro Na malha da rede: os impactos íntimos da internet, a autora discute novos conceitos e novas lógicas subjacentes a essa tecnologia, nos apresentando as implicações das novas formas de linguagem características da rede e as novas possibilidades de relacionamentos decorrentes do uso das salas de bate-papo. De fato, a autora ressalta a 
importância de estudos que investiguem profundamente os impactos que essa nova forma de comunicação e obtenção de informações ocasionará na vida das pessoas. Para ela, sem dúvida, a internet modificará a forma das pessoas sentirem, se relacionarem e se verem no mundo.

Este estudo procura explorar motivações, hábitos e atitudes em relação às salas de bate-papo na internet. $\mathrm{O}$ interesse principal será descrever os principais temas que os jovens abordam ou não nas salas de batepapo, assim como investigar suas opiniões sobre aspectos positivos e negativos da comunicação realizada neste ambiente.

A adolescência é uma fase do desenvolvimento oportuna para o estudo deste fenômeno, pois essa etapa de vida, tal como é concebida hoje, é produto de transformações ocorridas em nossa sociedade decorrentes da modernidade (Ruffino, 1993). Atualmente, o adolescente é visto tanto como particularmente sensível a mudanças sociais como gerador dessas transformações. Trata-se de um período no qual o indivíduo deve integrar suas experiências passadas às novas capacidades e habilidades emergentes, assim como as mudanças biológicas, cognitivas, emocionais e sociais na conquista de um senso de identidade (Erikson, 1971). Nesse sentido, as interações sociais assumem grande importância na medida em que se constituem em um espaço de experimentação e reflexão para a construção de uma nova representação de si.

\section{MÉTODO}

\section{Informantes}

Participaram desta pesquisa 128 jovens com média de idade 17,02 anos (desvio padrão $=1,13$ ), 61,7\% mulheres. Cerca de $83 \%$ eram estudantes de segundo e terceiro anos do ensino médio de uma escola particular da Grande São Paulo, e os demais eram alunos de primeiro ano do curso de Psicologia de uma universidade particular. A amostra não foi constituída por usuários assíduos às salas de bate-papo: $62,5 \%$ dos participantes indicaram utilizar as salas menos de uma vez por semana. Apenas $11,8 \%$ dos jovens da amostra declararam utilizar as salas de bate-papo quatro ou mais vezes por semana.

\section{Instrumento e Procedimentos}

Foi utilizado um questionário com questões abertas e fechadas investigando tópicos relacionados às moti- vações, hábitos e atitudes em relação às salas de batepapo na internet. Foram aplicados 174 questionários, contudo apenas 128 foram considerados válidos. Os critérios utilizados para a inclusão dos questionários neste estudo foram idade (entre 14 e 21 anos) e número de respostas válidas (pelo menos $70 \%$ das questões). Para a coleta dos dados foi apresentado o projeto de pesquisa à direção das instituições de ensino dos jovens, após a autorização das mesmas foram indicados turmas nas quais os jovens poderiam colaborar com o estudo, de acordo com a disponibilidade de horários.

O instrumento foi aplicado em sala de aula, após uma breve explicação acerca dos objetivos da pesquisa e do pedido de colaboração para o estudo. Eventuais dúvidas dos participantes foram esclarecidas antes da aplicação. Cuidados éticos foram tomados, para garantir o sigilo e confidencialidade das informações prestadas pelos jovens. Nenhum jovem recusou-se a participar da pesquisa. A aplicação durou aproximadamente 40 minutos.

\section{Análise dos Dados}

As análises realizadas foram basicamente descrições de frequiências e testes inferenciais para comparar as respostas de homens e mulheres. Para as respostas abertas dos questionários, foi utilizada uma análise de conteúdo, conforme Bardin (1977/1994), permitindo uma quantificação posterior dos resultados. As categorias foram definidas pela pesquisadora que fez uma primeira classificação das respostas, enquanto uma segunda classificação foi feita por outra pessoa em $20 \%$ dos questionários, usando os mesmos critérios. O nível de concordância obtido entre as duas classificações foi de $76 \%$. Os desacordos foram solucionados por consenso.

$\mathrm{Na}$ apresentação dos resultados relativos às questões abertas, o percentual de uma categoria refere-se à proporção de casos que puderam ser classificados dentro da categoria em relação ao total de casos válidos para a questão (casos com respostas em branco não foram incluídos nessas análises). Note-se que uma mesma resposta, dependendo do seu conteúdo, pode ter sido classificada em mais de uma categoria, o que faz com que a soma dos percentuais obtidos para as categorias dentro de uma mesma questão possa extrapolar o valor 100 . 


\section{RESULTADOS}

As frequiências dos motivos declarados para utilização das salas de bate-papo são exibidas na Tabela 1 (questão fechada com possibilidade de escolha de mais de uma alternativa). Estes resultados indicam que os principais objetivos dos jovens participantes deste estudo na utilização das salas de bate-papo foram a busca por diversão e pelo estabelecimento de novas relações (conhecer pessoas). Na categoria de "outros" objetivos os jovens citaram: passar o tempo, esperar enquanto estão realizando outros procedimentos na internet (por exemplo, download de programas e músicas) e conversar com amigos conheci- dos. Foi verificada uma diferença estatisticamente significativa entre os sexos no que se refere ao objetivo "procurar pessoas para sair", sendo que os homens assinalaram esse objetivo numa proporção maior do que as mulheres (de fato, nenhuma mulher marcou essa opção). Por outro lado, nenhum homem indicou o objetivo "arranjar um(a) namorado(a)" (embora as diferenças entre os sexos não tenham sido estatisticamente significativas). Outros objetivos para a utilização da rede que apresentaram uma proporção superior masculina, embora os testes estatísticos não tenham revelado diferenças significativas, foram evitar a solidão e ter relações sexuais virtuais.

Tabela 1: Motivações para utilização das salas de bate-papo

\begin{tabular}{lccc}
\hline Com que objetivo se conecta & \% Mulheres & \% Homens & \% Total \\
\hline Se divertir & 78,5 & 69,4 & 74,4 \\
Conhecer pessoas & 50,6 & 46,9 & 48,8 \\
Outros & 13,9 & 22,4 & 17,8 \\
Evitar a solidão & 7,6 & 16,3 & 10,9 \\
Se livrar de problemas/preocupações & 10,1 & 8,2 & 9,3 \\
Procurar pessoas para sair & 0,0 & 6,1 & 2,3 \\
Ter relações sexuais virtuais & 1,3 & 4,1 & 2,3 \\
Arranjar um(a) namorado(a) & 2,5 & 0,0 & 1,6 \\
\hline
\end{tabular}

*Teste para diferença de proporções estatisticamente significativo $(p=0,03)$

Na questão na qual os jovens foram questionados se costumam encontrar-se pessoalmente com as pessoas que conhecem através da internet não foram observadas diferenças percentuais significativas entre os sexos. Nota-se que as conversas estabelecidas nas salas de bate-papo parecem restringir-se à internet, uma vez que aproximadamente $80 \%$ dos jovens $(80,8 \%$ das mulheres e $77,5 \%$ dos homens) afirmaram nunca ou raramente encontrar pessoalmente as pessoas com quem conversam através das salas de bate-papo.

Já em relação à questão "Você se faz passar por alguém diferente na internet?" observou-se que um maior número de mulheres indicou se passar por outra pessoa nas salas de bate-papo quando comparadas aos homens (cerca de 56\% contra 36\%), e vice-versa, sendo esta associação entre sexo e resposta estatisticamente significativa ( $p=0,04$; teste de Fisher).

Os principais tipos de informação pessoal que os pesquisados relataram modificar quando conversam nas salas de bate-papo são exibidos na Tabela 2 (questão aberta). Observa-se que idade, nome e aparência física foram os três aspectos mais citados pelos sujeitos, considerando-se ambos os sexos, com destaque para idade, com mais de $60 \%$ de referências espontâneas. Não foram observadas diferenças estatisticamente significativas $(p>0,05)$ nos percentuais de homens e mulheres em cada categoria.

Tabela 2: Tipos de dados pessoais que são modificados na internet

\begin{tabular}{lccc}
\hline Quais dados troca & \% Mulheres & \% Homens & \% Total \\
\hline Idade & 56,3 & 66,7 & 60,5 \\
Nome & 50,0 & 45,5 & 48,1 \\
Aparência física & 31,3 & 42,4 & 35,8 \\
Personalidade & 35,4 & 24,2 & 30,9 \\
Endereço & 27,1 & 33,3 & 29,6 \\
Sexo & 22,9 & 27,3 & 24,7 \\
Nada & 6,3 & 18,2 & 11,1 \\
Outras respostas & 8,3 & 2,9 & 6,1 \\
\hline
\end{tabular}


No que se refere aos motivos que levavam os sujeitos a modificar os seus dados pessoais na rede, não foram observadas diferenças percentuais significativas. Os principais motivos foram: segurança/não se expor $(36,7 \%)$, diversão $(22,4 \%)$ e liberdade para falar o que quer $(6,1 \%)$. Cabe observar que $12,2 \%$ dos jovens afirmaram não modificar seus dados pessoais na rede.

As principais categorias de assuntos abordados pelos jovens em suas conversas nas salas de bate-papo encontram-se listadas na Tabela 3, com suas respectivas freqüências: total e por sexo (questão aberta). A categoria mais citada foi "gostos e interesses", com cerca de $33 \%$ das respostas incluídas sob este rótulo (considerando-se o total). Em contraste, "aspectos da vida pessoal" e "sexo" foram as categorias menos frequientes, com aproximadamente $9 \%$ e $2 \%$ das respostas, respectivamente. Não foram observadas diferenças estatisticamente significativas $(p>0,05)$ nas proporções de homens e mulheres em cada categoria.

Tabela 3: Temas sobre os quais os adolescentes conversam nas salas de bate-papo

\begin{tabular}{lccc}
\hline Temas sobre os quais conversa & \% Mulheres & \% Homens & \% Total \\
\hline Sobre gostos e interesses & 35,4 & 28,9 & 33,1 \\
Sobre o dia a dia & 22,8 & 20,0 & 21,8 \\
Sobre qualquer assunto & 17,7 & 22,2 & 19,4 \\
Sobre assuntos gerais & 19,0 & 17,8 & 18,5 \\
Sobre outra coisa & 15,2 & 13,3 & 14,5 \\
Sobre vida pessoal & 12,7 & 2,2 & 8,9 \\
Sobre sexo & 1,3 & 4,4 & 2,4 \\
\hline
\end{tabular}

A Tabela 4 apresenta as freqüências observadas nas categorias relativas aos assuntos que os jovens não conversariam nas salas de bate-papo, por sexo e total (questão aberta). Observa-se que o assunto mais rejeitado para conversas nas salas virtuais é "vida pes- soal", com cerca de $47 \%$ de referências (no total). Apenas para o assunto "sexo" a diferença de percentuais observada entre homens e mulheres foi estatisticamente significativa $(\mathrm{p}<0,05)$.

Tabela 4: Temas sobre os quais os adolescentes não conversariam nas salas de bate-papo

\begin{tabular}{lccc}
\hline Temas sobre os quais não conversariam & \% Mulheres & \% Homens & \% Total \\
\hline Sobre minha vida pessoal & 53,9 & 36,2 & 47,2 \\
Sobre sexo e pornografia & 34,2 & 6,4 & 23,6 \\
Sobre outra coisa & 11,8 & 25,5 & 17,1 \\
Não teria restrições de assuntos & 13,2 & 19,1 & 15,4 \\
Sobre meus dados pessoais & 5,3 & 4,3 & 4,9 \\
Sobre religião & 2,6 & 8,5 & 4,9 \\
Sobre bobagens & 3,9 & 4,3 & 4,1 \\
\hline
\end{tabular}

Com relação à questão que perguntava se existiam assuntos que os participantes falariam apenas na internet, observou-se que mais de $70 \%$ das respostas foi negativa a esta questão. Esse dado nos sugere que a rede não é vista como um ambiente tão propício para a exposição de si, como alguns autores sugerem.

Ainda questionou-se os jovens: "você acha mais fácil falar de assuntos íntimos na internet?", observando-se uma associação estatisticamente significativa entre o sexo e resposta ( $p=0,02$; teste de Fisher). Um percentual significativamente maior de homens referiu achar mais fácil falar de temas íntimos na in- ternet em comparação às mulheres $(49 \%$ de homens contra 27,8\%). Os homens também indicaram sentirse mais protegidos para falar nas salas de bate-papo (comparativamente às interações face a face) do que as mulheres (embora o nível de significância para o teste de associação entre sexo e resposta tenha sido um pouco acima do usualmente aceito como significativo: $p=0,07$; teste de Fisher). Observa-se que $37,5 \%$ dos homens responderam afirmativamente a questão em comparação a $21,5 \%$ das mulheres. Contudo, a maioria dos jovens não considera que as conversas que estabelecem nas salas de bate-papo lhes 
auxiliam a se conhecer melhor ( $75 \%$ responderam que não), não sendo observada associação estaticamente significativa entre sexo e resposta $(p=0,53$; teste de Fisher).

Poucos jovens parecem buscar ajuda para resolver seus problemas nas salas de bate-papo na internet (apenas 11\% declararam usar a rede com este intuito). Neste aspecto também não foi observada associação estaticamente significativa entre sexo e resposta ( $p=0,77$; teste de Fisher).

Ao avaliarem a qualidade das suas conversas nas salas de bate-papo, os jovens consideraram que estas são, principalmente, divertidas $(29,3 \%)$, superficiais/ fúteis $(26 \%)$, inúteis $(21,1 \%)$ e mentirosas $(15,4 \%)$. Apenas $7,3 \%$ das respostas indicaram que as conversas estabelecidas nas salas de bate-papo servem para conhecer pessoas. Neste último item, observa-se uma diferença significativa na opinião de homens e mulheres: enquanto $14,9 \%$ dos jovens do sexo masculino acreditam que as conversas na rede servem para conhecer pessoas, apenas $2,6 \%$ das meninas possuem essa crença.

A Tabela 5 apresenta as respostas dadas à questão que abordava o que os jovens percebiam como interessante nas salas de bate-papo (questão aberta). As categorias de respostas mais salientes foram: "nada interessante" (com frequiência de 22\%) e "possibilidade de trocar informações com pessoas de todo o mundo" (com 21\%). Não foram observadas diferenças estatisticamente significativas $(p>0,05)$ nas proporções de homens e mulheres em cada categoria.

Tabela 5: Opiniões sobre o que é interessante nas salas de bate-papo

\begin{tabular}{lccc}
\hline O que é interessante & \% Mulheres & \% Homens & \% Total \\
\hline Não acha nada interessante & 21,5 & 22,0 & 21,7 \\
A possibilidade de trocar informações & 20,3 & 22,0 & 20,8 \\
com pessoas de todo o mundo & & & \\
Poder se divertir & 19,0 & 12,2 & 16,7 \\
Outras respostas & 17,7 & 14,6 & 16,7 \\
A possibilidade de conhecer pessoas & 12,7 & 19,5 & 15,0 \\
Não ser reconhecido (anonimato) & 7,6 & 7,3 & 7,5 \\
Poder mentir & 2,5 & 2,4 & 2,5 \\
\hline
\end{tabular}

Já a Tabela 6 mostra as frequiências para as categorias de respostas na questão relativa ao que os jovens consideravam inconveniente nas salas de bate-papo (questão aberta). Observa-se que, analisando homens e mulheres em conjunto, o fator considerado mais inconveniente pelos participantes do estudo é não saber se o que é dito nas salas é verdadeiro ou não, com cerca de $20 \%$ de referências; em seguida, destaca-se a categoria "falta de educação", com aproxima- damente $19 \%$. Deve-se ressaltar, contudo, que as diferenças nas proporções de homens e mulheres para as categorias "invasão da vida pessoal" e "não vê inconveniente" foram estatisticamente significativas $(p<0,05)$, com mais mulheres do que homens achando a invasão de privacidade um inconveniente e mais homens do que mulheres não vendo inconvenientes nas conversas das salas de bate-papo (as demais comparações não foram significativas).

Tabela 6: Opiniões sobre o que é inconveniente nas salas de bate-papo

\begin{tabular}{lccc}
\hline O que é inconveniente & \% Mulheres & \% Homens & $\%$ Total \\
\hline Não saber se as pessoas estão mentindo & 17,3 & 23,3 & 19,5 \\
A falta de educação & 20,0 & 16,3 & 18,6 \\
A invasão da vida pessoal (perguntas indiscretas) & 20,0 & 0,0 & 12,7 \\
Outras respostas & 12,0 & 14,0 & 12,7 \\
Não vê inconveniente & 6,7 & 18,6 & 11,0 \\
A superficialidade dos assuntos & 10,7 & 9,3 & 10,2 \\
Não conhecer as pessoas & 6,7 & 7,0 & 6,8 \\
A falta de segurança & 6,7 & 4,7 & 5,9 \\
Tudo & 4,0 & 9,3 & 5,9 \\
\hline
\end{tabular}




\section{DISCUSSÃO}

A maior parte dos jovens dessa amostra não estava habituada a dispensar muito tempo na utilização das salas de bate-papo (menos de uma hora), assim como não costumava acessar freqüientemente as salas. $\mathrm{O}$ uso das salas de bate-papo foi predominantemente associado à diversão e ao conhecimento "superficial" de pessoas. Poucos jovens estendiam as relações estabelecidas pela internet às suas experiências presenciais de encontro com o outro. Esses dados diferem dos encontrados no estudo de Civiletti e Pereira (2002) que buscou analisar as relações afetivo-sexuais mediadas nas salas de bate-papo virtual com adultos. Nesse estudo, os autores encontraram que metade de sua amostra desejava estender os encontros realizados na internet para suas relações presenciais, especialmente se não percebiam diferenças entre as relações estabelecidas nas salas de bate-papo e as face a face. No estudo referido, ainda, $37,1 \%$ dos participantes desejava o estabelecimento de relações afetivo-sexuais enquanto em nossa amostra apenas 4,6\% eram motivados por essa finalidade (arranjar namorado ou procurar pessoas para sair). As diferenças encontradas entre os estudos podem decorrer tanto das discrepâncias nas motivações para a utilização das salas de bate-papo como da faixa etária estudada. Em nosso caso, os adolescentes parecem encarar as relações na rede a partir de uma perspectiva mais lúdica que os adultos, o que os leva a não se comprometerem em tais relações e, talvez, não criarem muitas expectativas em relação aos parceiros e às próprias possibilidades da comunicação via internet. De fato, as salas de batepapo para esses jovens parecem servir mais como um meio de descontração onde assuntos sérios não são muito abordados.

Os jovens demonstraram interesse em se divertir e passar seu tempo, possivelmente conversando com outros acerca de seus gostos e interesses, assuntos gerais como política e esporte (entre outros) ou então suas atividades cotidianas de maneira superficial. Os jovens não parecem considerar estes temas como pertencentes a sua esfera íntima (vida pessoal). Pode-se observar que apenas aproximadamente $9 \%$ dos jovens responderam que conversa nas salas de bate-papo sobre vida pessoal. Aproximadamente metade deles apontou ter restrições a abordar aspectos de sua vida pessoal nas salas de bate-papo, considerando um inconveniente a invasão de privacidade possibilitado pela internet.

Esses dados estão em desacordo com as idéias de Cooper e Sportolari (1997) que supõem que as pessoas se revelam mais e de forma mais rápida através da comunicação mediada por computador do que elas fariam em suas relações face a face. A internet, para estes autores, possibilitaria um maior controle do espaço pessoal que existe nas relações interpessoais. Este espaço autônomo, que pode ser facilmente invadido por outros nas interações cotidianas, seja fisicamente ou psicologicamente, estaria mais preservado nas relações estabelecidas através do computador, facilitando dessa forma a revelação ao outro. Contudo, os jovens deste estudo parecem se restringir a abordar assuntos mais superficiais e periféricos acerca de si mesmo, sentindo-se incomodados ao receberem perguntas consideradas indiscretas. Aparentemente, não existe um interesse maior na revelação de aspectos mais íntimos, pois as relações ali estabelecidas são vistas como um mero passatempo ou pouco confiáveis (mentirosas). É interessante observar que os dados indicam uma tendência: as mulheres sentem-se mais incomodadas do que os homens quando são realizadas perguntas indiscretas, principalmente as que abordam o tema sexualidade.

Alguns autores supõem que as salas de bate-papo, por possibilitarem o anonimato e o uso da imaginação/criação de personagens, poderiam estar revolucionando o falar-de-si, as relações interpessoais e a própria identidade dos indivíduos. Turkle (1995) e Suller (2000) consideram que a ausência de identificação e de contato físico possibilitariam a exploração do outro e de si próprio num ambiente de relativo controle e segurança. A falta de pistas de orientação, comuns nas interações face a face, daria a oportunidade de construção e experimentação de diferentes personagens, dentro de um contexto considerado como seguro e lúdico. A proteção oferecida pelo anonimato permitiria a experimentação de papéis e a realização virtual de fantasias que não seriam admissíveis ou possíveis para a maioria das pessoas na vida real de forma desinibida. Nesta amostra, entretanto, observou-se que poucos sujeitos indicaram essas características como vantagem para a utilização da rede. Se observarmos as categorias de resposta da questão que trata dos aspectos considerados interessantes na comunicação via sala de bate-papo, apenas $10 \%$ dos participantes fizeram uma referência espontânea às características anonimato e possibilidade de criação de personagens (ou mentira). Na verdade, o anonimato parece estar mais associado aos inconvenientes dessa forma de comunicação do que aos seus possíveis aspectos interessantes. De fato, a "mentira" (impossibilidade de saber se o que é dito nas salas é verdade ou não), o "não conhecer as pessoas" e a "falta de segurança" produzidas 
pelo anonimato foram as principais categorias de inconvenientes citadas pelos jovens desta amostra.

Apesar de considerado pouco interessante, o anonimato permitiu à metade dos jovens desta amostra se passar por alguém diferente nas suas interações nas salas de bate-papo, sendo observado que um percentual significativamente superior de mulheres utilizou-se desse recurso. Possivelmente as meninas construam e se sintam mais aptas à criação de personagens, pois estendem suas habilidades relacionais das interações face a face para o ambiente virtual. Mesmo na rede, parecem encontrar-se mais preocupadas em conversar e estabelecer um contato de algum modo significativo com o outro, o que podem fazer lançando mão da imaginação. Já os meninos, quando resolvem criar um personagem (mentindo na rede), não parecem possuir intenções relacionais ou de conhecimento do outro. Pode-se observar que esse personagem geralmente assume um caráter de agressão ou contestação do outro. Algumas respostas masculinas oferecidas à questão "por que se faz passar por alguém diferente?" são ilustrativas: "Pra zuar as fãzinhas babacas desse cara" - "Para zoar, inventei um nick 'Lomburda', teclei com várias garotas e garotos, marquei vários encontros e não fui a nenhum". Nenhuma menina ofereceu justificativa similar, embora ambos os sexos tenham se referido à diversão como motivo para criação de personagens. Apesar das ilustrações, são necessários mais estudos para verificar a pertinência da interpretação proposta.

O principal dado modificado pelos jovens foi idade, sendo seguido pelo nome. É possível que esses jovens alterem suas idades para poderem se relacionar com pessoas mais velhas, e serem aceitos pelas mesmas. A troca da idade permite aos jovens, nesse momento do desenvolvimento, explorar e experenciar papéis mais "adultos". Na verdade, os jovens podem ou estar buscando verificar se já possuem idéias e comportamentos suficientemente maduros (através da validação que o outro pode dar as suas "ações") ou ainda podem estar testando como se sentem encenando um papel adulto. O nome, freqüentemente, é modificado nas interações estabelecidas nos chats, pois é ele que oferece os primeiros indícios de identidade do personagem ou mesmo para o estabelecimento da relação. Campos (2001) afirma que o nick (nome atribuído na rede) é a identidade do internauta nas salas de bate-papo; é ele que o apresenta, oferecendo vários indícios acerca da identidade real de seu portador.

Ainda que não tenham sido observadas diferenças significativas nas demais características modificadas nas salas de bate-papo, é interessante destacarmos os percentuais observados para as categorias aparência física (na qual o percentual de homens foi maior que o de mulheres) e personalidade (onde ocorreu o inverso). Essa tendência pode ser explicada através das diferenças de gênero tradicionalmente observadas em nossa sociedade ocidental. O homem, de modo geral, é mais avaliado por seus atributos físicos e capacidade para realização/empreendimento enquanto as mulheres são mais julgadas por aspectos relacionais e afetivos. Ainda outra diferença associada aos estereótipos culturais vinculados aos papéis de gênero foi a preferência masculina por abordar temas relacionados à sexualidade e pornografia.

As salas de bate-papo não foram percebidas como um recurso para falar de problemas pessoais. De fato, poucos jovens admitiram discutir seus problemas na rede. Os adolescentes não consideram que as conversas ali desenvolvidas lhes auxiliem a se conhecer melhor. Da mesma forma, as salas não são lugares preferenciais para a revelação de si. No entanto, os resultados parecem apoiar parcialmente as idéias de Merkle e Richardson (2000). Esses autores acreditam que a rede oferece a possibilidade de desvinculação dos estereótipos sexuais, uma vez que as diferenças de gênero encontradas na revelação de si face a face poderiam ser diminuídas ou mesmo apagadas na internet. A rede, ao possibilitar o anonimato, oportunizaria que homens possam falar mais abertamente de seus sentimentos e emoções, sem as preocupações de pôr em risco a sua imagem pessoal, enquanto as mulheres também se mostrariam mais livres para revelarem desejos secretos. Neste estudo, observou-se uma tendência dos informantes do sexo masculino a se sentirem mais protegidos para falarem acerca de assuntos pessoais na rede, assim como acharem mais fácil de falar assuntos íntimos. Já as meninas não pareceram interessadas em discutir assuntos íntimos, especialmente relacionados à sexualidade. Talvez essa recusa esteja associada ao baixo nível e à falta de seriedade com que esses assuntos parecem ser tratados através desse meio de comunicação.

Por fim, cabe observar que as salas de bate-papo, embora ofereçam oportunidades para a revelação de si íntima sem os riscos e os comprometimentos das interações face a face, não parecem se constituir em lugares apropriados para a revelação de si na percepção destes jovens. As salas de bate-papo são percebidas preferencialmente como lugares de diversão nos quais podem ser estabelecidas novas relações através de conversas leves e superficiais que abordam infor- 
mações periféricas de si mesmo ou então temas mais gerais do cotidiano.

Algumas ressalvas metodológicas precisam ser feitas neste estudo. Em primeiro lugar, a amostra utilizada na pesquisa não foi aleatória e nem pode ser considerada representativa de toda população de adolescentes usuários da internet. Ela foi composta em sua maioria por pessoas que não utilizavam as salas de bate-papo regularmente, o que pode ter introduzido algum viés nos resultados. Talvez outros perfis de usuários apresentem comportamentos e interesses diferenciados. Em segundo lugar, algumas limitações do próprio instrumento devem ser indicadas. Trabalhamos com a classificação de respostas muitas vezes lacônicas e pouco informativas, o que pode ter provocado equívocos na interpretação das mesmas. Buscamos reduzir esses efeitos através da utilização de dois codificadores; contudo, os resultados aqui apresentados precisam ser considerados com cautela. Futuras pesquisas que superem essas limitações metodológicas se fazem necessárias para que se possa corroborar (ou não) os achados deste estudo.

\section{REFERÊNCIAS}

Bargh, J. A., McKenna, K. Y. A. \& Fitzsimons, G. M. (2002). Can you see real me? Activation and expression of the "true self" on the internet. Journal of Social Issues, 58, 33-48.

Berton, P. (2000). Le culte à l'internet. P.U.F: Paris.

Campos, I. V. (2001). Os nicks nas salas de chat (bate-papo). Obtido em 07 de janeiro de 2003 do World Wide Web: http://www.pucsp.br/clinica/salachat.html.

Civiletti, M. V. P. \& Pereira, R. (2002). Pulsões contemporâneas do desejo: Paixão e libido nas salas de bate-papo virtual. Psicologia Ciência e Profissão, 22, 38-49.

Cooper, A. \& Sportolori, L. (1997). Romance in cyberspace: Understanding online attraction. Journal of Sex Education and Therapy, 22, 7-14.
Erikson, E. (1971). Identidade, juventude e crise. (A. Amado, Trad.) Rio de Janeiro: Zahar. (Originalmente publicado em 1968)

Griffits, M. D. (2000). Excessive internet use: Implications for sexual behavior. Cyberpsychology and Behavior, 3, 537-552.

Griffits, M. D. (1997). Children and internet. Media Education Journal, 21, 31-33.

Ibope (2002). 11 ${ }^{a}$ Pesquisa. Obtido em 05 de setembro de 2002 do World Wide Web: http://www.ibope.com.br/digital/produtos/internetpop.

Ibope (2004). Brasileiros batem novo recorde de navegação na internet. Obtido em 20 de junho de 2005 do World Wide Web: http://www.ibope.com.br/calandraWeb/servlet/CalandraRedire ct?temp.

Lajoie, J. (1998). Les moteurs de recherche du réseau internet comme indicateurs des besoins intimes. Révue Québécoise de Psychologie, 19, 207-229.

Leon, D. T. \& Rotunda, R. J. (2000). Contrasting case studies of frequent internet use: Is it pathological or adaptative? Journal of College Student Psychoterapy, 14, 9-18.

Merkle, E. R. \& Richardson, R. A. (2000). Digital dating and virtual relating: Conceptualizing computer mediated romantic relationships. Family Relations, 49, 187-192.

Nicolaci-da-Costa, A. M. (1998). Na malha da rede: Os impactos intimos da internet. Rio de Janeiro: Ed. Campus.

Ruffino, R. (1993). Sobre o lugar da adolescência na teoria do sujeito. Em C. Rappaport (Org.), Adolescência: Abordagem psicanalítica. (pp. 25-58). São Paulo: E.P.U.

Schnarch, D. (1997). Sex, intimacy, and internet. Journal of Sex Education Therapy, 22, 15-20.

Suller, J. (2000). Hypotheses about online text relationships. Obtido em 04 de fevereiro de 2001 do World Wide Web: http://www.rider.edu/users/suler/psycyber/textrel.html.

Turkle, S. (1995). Life on the screen: Identity in the age of the internet. New York: Touchstone.

Wysocki, D. K. (1998). Let your fingers do the talking: Sex on an adult chat-line. Sexualities, 1, 425-452.

Recebido: $15 / 09 / 2005$ Revisado: 01/05/2006 Aceito: 07/07/2006

\section{Sobre os autores:}

Ana Cristina Garcia Dias: Doutora em Psicologia Escolar e do Desenvolvimento USP/São Paulo. Professora nos cursos de Psicologia do Centro Universitário Franciscano (UNIFRA - Santa Maria) e da Universidade Regional Integrada do Alto Uruguai (URI - Campus de Erechim). Endereço eletrônico:cristcris@ hotmail.com.

Yves de La Taille: Professor Livre-Docente do Instituto de Psicologia da USP. Autor, entre outros livros, de Limites: Três dimensões educacionais (Ática, 1998) e Vergonha: a ferida moral (Vozes, 2002). 